\title{
CONCEITO PSICOSSOMÁTICO DA ENFERMAGEM
}

\section{Psychosomatic Concepts of Nursing}

El concepto psicosomático de la Enfermería

\section{Apresentação}

Maria Angélica de Almeida Peres ${ }^{1}$

O fac-símile intitulado "Conceito Psicossomático da Enfermagem", de autoria da Enfermeira Maria de Lourdes Verderese, à época Professora da Escola de Enfermagem de São Paulo, foi publicado nos Anais de Enfermagem de julho de 1948, vol. I, n. 3, p. 107-109.

Partindo do reconhecimento da influência do campo psicossomático na saúde do ser humano, o texto discorre sobre os seus desdobramentos para a assistência de enfermagem e valoriza a observação do comportamento humano como forma de individualizar o cuidado.

A autora chama atenção para a observação científica na enfermagem, o que demonstra preocupação com o desenvolvimento da profissão. Traz também sua experiência nos Estados Unidos, onde se buscava o aprendizado para conciliar o conceito psicossomático à prática da enfermagem.

Trata-se de um texto de grande importância histórica, por mostrar ao leitor a intenção, na década de 40 do século XX, de se conduzir a prática e o ensino de enfermagem, considerando o meio sociocultural e emocional em que o indivíduo está inserido, como fator fundamental para a prevenção e a cura de doenças.

A publicação original encontra-se no Centro de Documentação da Escola de Enfermagem Anna Nery da Universidade Federal do Rio de Janeiro (EEAN/UFRJ). 


\section{Presentation}

Maria Angélica de Almeida Peres ${ }^{1}$

The present facsimile entitled "Psychosomatic Concepts of Nursing," written by Nurse Maria de Lourdes da Verderese - at the time - Professor of the Nursing School in San Paulo, was published in the Anais da Enfermagem (Annals of Nursing), July 1948, Vol. I, Nr. 3, p 107-109.

By recognizing the influence of the psychosomatic field in the health of human beings, the text analyses its development applied to nursing care. It also highlights the importance of the observation of human behavior as a form to provide individualized health care.

The author draws the attention to the importance of scientific observation in the nursing field. This proves her concern with the development of the profession. She also shares her experience in the United States, where the learning process strived to bring together the psychosomatic concept with the practice of nursing.

This text has a great historical value because it shows the readers the intention - in the forties - 20th century - to guide the practice and teaching of nursing, taking into consideration the socio-cultural and emotional factors in which the individuals are inserted as a major factor for the prevention and cure of diseases.

The original publication can be found at the Documentation Center of the School of Nursing Anna Nery Federal University of Rio de Janeiro (EEAN / UFRJ).

\section{Presentación}

Maria Angélica de Almeida Peres ${ }^{1}$

El presente facsímil intitulado "El concepto psicosomático de la Enfermería", cuya autora es la enfermera Maria de Lourdes Verderese - que en la época era profesora de la Escuela de Enfermería de San Paulo fue publicado en los Anales de la Enfermería de julio de 1948, Vol.1 • № 3, páginas 107-109.

A partir del reconocimiento de la influencia del campo psicosomático en la salud del ser humano, el texto analiza el desarrollo de la misma en el campo de la asistencia de la enfermería y valoriza la observación del comportamiento humano como forma de individualizar el cuidado.

La autora llama la atención hacia la observación científica en la enfermería, lo que demuestra que está preocupada con el desarrollo de la profesión. Aporta también su experiencia en los Estados Unidos, donde se intentaba que el aprendizaje conciliase conceptos psicosomáticos con la práctica de la enfermería.

Este texto es de gran importancia histórica, porque demuestra a los lectores la intención, en la década de los cuarenta - del siglo 20 - de guiar la práctica y la enseñanza de la enfermería, tomando en consideración el medio sociocultural y emocional en el cual el individuo se encontraba inserido como un factor indispensable en la prevención y cura de enfermedades.

La publicación original se encuentra en el Centro de Documentación de la Escuela de Enfermería Anna Nery de la Universidad Federal de Río de Janeiro (EEAN/UFRJ). 


\title{
CONCEITO PSTCO-SOMÁTICO \\ DA ENFERMAGEM (*)
}

\author{
MARIA DE LOURDES VERDERESE (**)
}

A medicina redescobriu recentemente, um fato - ha muito reconhecido em outros campos - de que o homem funciona como uma entidade psico-somática, quer na doença, como na saúde e de que ha uma intèr-relação inseparável entre o homem e o meio em que vive, ou a que se ajusta. $\hat{\mathbf{E}}$ isto, sómente isto, que constitue a tão falada e discutida medicina psico-somática, de hoje em dia. A medicina vem perdendo aquela tendência de se esquecer, de perder o paciente na multidão de fatos colhidos sôbre seus orgãos e sistemas.

E a enfermagem, vem acompanhando a medicina... As enfermeiras passaram a reconhecer e reconhecem cada vez mais: que as emoçôes têm influência sôbre o corpo e o corpo sôbre as emoções. Elas já não ignoram — que os problemas emocionais, Ge natureza social, são fatores significativos durante a doença do paciente, na rapidez de uma cura, na aparente relutância que demonstra o paciente em confessar que se sente melhor para não retornar a um ambiente que considera insatisfatório.e, muitas vezes, desagradavel. Dia a dia se reconhece mais que é impossível tratar construtivamente uma pessoa doente, quando ignoramos ou nos esquecemos de suas preocupações, ansiedades e prostraçoes relacionadas com suas responsabilidades no lar, no trabalho, com suas experiências passadas, com a moléstia, com a possibilidade ou não de uma cura ou uma possivel incapacidade física resultante dessa doença.

A enfermagem psico-somática, nada mais é, que uma extensão dos conhecimentos e práticas que sempre caracterizaram a enfermagem, mas uma extensão real, significativa e que já não pode ser negligenciada. Ela envolve o simples reconhecimento do padrão de que a cólera eleva a pressão arterial, de que o mêdo

(*) Trabalho apresentado na reunião da ABED., Seção de São Faulo, em Abril de 1948.

(*) Professora da Escola de Enfermagem de S. Paulo. 
causa diarrea, a ansiedade - suores frios, de que o perigo impede a digestão, etc.

A evidência nos tem mostrado de que, quando o equilibrio emocional se torna crônico, as mudanças psicologicas acarretadas por êsse desiquilibrio podem, também, tornar-se crônicas e causar um mal irreversível. Se estudarmos cuidadosamente uma grande variedade de condiçóes tais como a úlcera péptica. a hipertensão essencial, a asma bronquica, o hipertireoidismo, a colite mucosa ou ulcerativa e uma grande variedade de moléstias da pele, encontramos entre os maiores fatores causadores dessas dificuldades - o fator emocional. Para que se possa compreender a etiologia de tais condiçoes e planejar uma terapia racional, é necessário o estudo da personalidade do paciente e dos problemas emocionais contra os quais êle muitas vezes procura reagir, mas falha.

Já é tempo para que nós enfermeiras substituamos o chamado "senso comum" por uma observação científica e estudo do comportamento humano. Um cuidado adequado - médico e de enfermagem - requer individualização do tratamento, com a devida consideração para com as atitudes do paciente, suas necessidades emocionais e problemas pessoais que possam ter con. corrido para a doença e estăo, agora, a impedir a cura.

$\mathrm{E}$ inutil pensar em controlar a diabete, emquanto o paciente não puder dominar o desejo invencivel de comer doces. cada vez que é negligenciada pelo marido. Uma paciente com colite alcerativa pode sofrer uma recaida cada vez que seu marido a visite.

Um homem com úlcera péptica está tendo uma segunda hemorragia e provavelmente nunca se restabelecerá a não ser que suas dificuldades conjugais sejam removidas.

Uma senhora com dermatite nâo pode deixar de se cocar. Esta paciente se recusará a comer, aquela outra provavelmente. não poderá párar de comer.

São êsses - pergunto - casos médicos ou casos puramente psiquiátricos? De ambas. Essas duas disciplinas - medicina e psiquiatria - se fundirão para uma melhor contribuição ao cuidado mais adequado do paciente. Não ha um só paciente que não possa ser auxiliado pela compreensão.

o tratamento de um paciente deve ser, também, e sobretu. do dirigido aos fatores emocionais e sociais que causaram tais disturbios. As enfermeiras devem, portanto, estar a par do dinamismo no desenvolvimento da personalidade, do papel que de- 
sempenha o meio nos ajustamentos humanos e das terapêticas emocionais dentro - é claro - de suas prerrogativas e responsabilidades.

Durante nossa experiểncia - como estudante - em "The Johns Hopkins Hospital - mórmente nestes últimos anos - a aossa Escola empreendeu um esforço ral na preparação das estudantes para a prática da enfermagem psico-somática.

Úm curso de psicologia-social é dado às alunas, durante o período pré-clínico. Segue-se um período clínico de quatro semanas - num departamento de psiquiatria - onde a enfase é posta nas desordens menores - sociais - emocionais - da personalidade e nos principios e práticas para a prevenção de desajustamentos psico-somáticos.

Durante todo o tempo, e, em todas as enfermarias procurase conciliar o conceito psico-somático com a prática da enfermagem.

Quando no terceiro ano, as alunas voltam ao Departamento de Psiquiatria, por um período de oito semanas. Agora a enfase é posta nas desordens maiores - sociais e emocionais da personalidade e as alunas participam do cuidado desses pacientes, salientando-se, ainda, princípios e práticas de prevenção.

Um tal programa tem como objetivo 1) ajudar a enfermeira a adquirir um maior grau de eficiência no cuidado integral do paciente - paciente este considerado como uma pessoa na sua relação como o grupo cultural a que pertance. 2) torná-la de posse de certos princípios práticos afim de que essas desordens emocionais que alejam o individuo e a sociedade possam ser prevenidas.

Ainda mais - um curso de dezesseis semanas sôbre conceito psico-somático e enfermagem psico-somática é dado - em carater compulsório - a todas as enfermeiras diplomadas que traibalham no hospital. 